\title{
Poesia, instante vertical e solidão na fenomenologia poética de Gaston Bachelard
}

\section{Poetry, vertical instant and loneliness in poetic phenology of Gaston Bachelard}

DOI: $10.12957 / \mathrm{ek} .2016 .22800$

Ms. Fernando da Silva Machado f.silva.machado@bol.com.br Universidade Federal de Goiás - GO

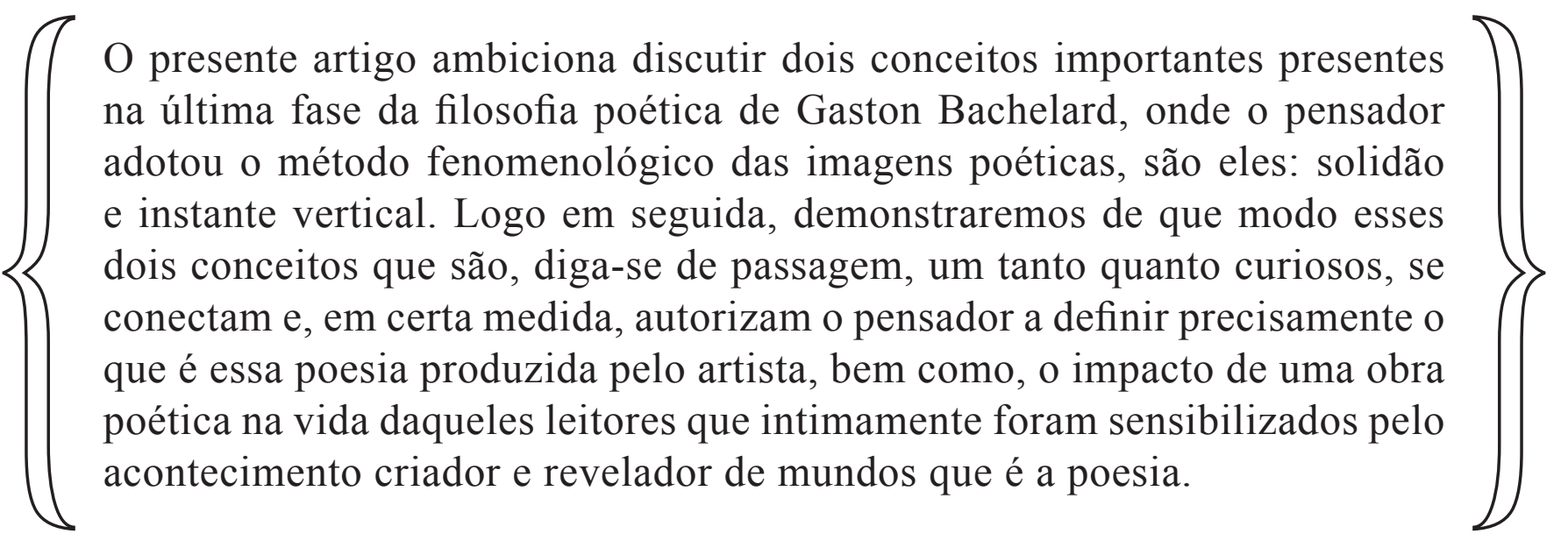

PALAVRAS-CHAVE Bachelard. Fenomenologia. Poesia. Instante Vertical. Solidão

This article wants to discuss two important concepts present in the last phase of the poetic philosophy of Gaston Bachelard, who adopted the phenomenological method of poetic images, they are: loneliness and vertical instant. Shortly thereafter, we will demonstrate how these two concepts that are, by the way, somewhat curious, connect and, to some extent, authorize the thinker to define precisely what is this poetry produced by the artist, as well as the impact of a poetic work in the lives of those readers who closely were sensitized that phenomenological event creator and developer of worlds that is poetry.

KEYWORDS Bachelard. Phenomenology. Poetry. Instant Vertical. Loneliness 
Poesia, instante vertical e solidão na fenomenologia poética de Gaston Bachelard
Ms. Fernando da Silva Machado [FAFIL-UFG]

\section{Introdução \\ Que fenomenologia poética é essa praticada por Bachelard ?}

A partir de sua obra "La poétique de le espace" (1957), Bachelard modifica seu ponto de vista e a maneira de conduzir seus estudos a respeito da imagens. Ele substitui sua interpretação psicanalítica das imagens materiais pelo método fenomenológica da imaginação. Essa mudança de um método psicanalítico das imagens para um método fenomenológico das imagens demarca a grande modulação que sofreu sua filosofia poética. Em suas últimas três obras noturnas Bachelard renuncia abertamente o vocabulário da psicanálise clássica para adotar um vocabulário puramente fenomenológico (LECOURT, 1974, p.123). A esse respeito Bachelard (1977, p. 184) diz:

Em nossos trabalhos anteriores sobre a imaginação, tínhamos considerado preferível situar-nos, tão objetivamente quanto possível, diante das imagens dos quatro elementos da matéria, dos quatro princípios das cosmogonias intuitivas. Fiel a nossos hábitos de filósofo das ciências, tínhamos tentado considerar as imagens fora de qualquer tentativa de interpretação pessoal. Pouco a pouco, esse método, que tem a seu favor a prudência científica, pareceu-nos insuficiente para fundar uma metafísica da imaginação.

O alerta dado pelo filósofo versa que se quisermos adentrar no reino da imaginação, em busca da novidade do instante poético das imagens libertadoras de mundos, cada indivíduo praticante de um racionalismo ativo deve necessariamente romper de imediato com seus hábitos de pesquisa. "Por sua novidade, por sua atividade, a imagem poética tem um ser próprio, um dinamismo próprio. Ela advém de uma ontologia direta. É com essa ontologia que desejamos trabalhar" (BACHELARD, 1978, p. 183). Bachelard havia percebido que sua primeira interpretação das imagens materiais estava sobrecarregada de objetividade. Em um segundo momento, partindo do método fenomenológico da imaginação, o filósofo tentou restituir o caráter subjetivo, próprio das imagens, que segundo ele não havia sido tangenciado em sua primeira interpretação.

Fiel a nossos hábitos de filósofo das ciências, tínhamos tentado considerar as imagens fora de qualquer tentativa de interpretação pessoal. Pouco a pouco, esse méto- 
Poesia, instante vertical e solidão na fenomenologia poética de Gaston Bachelard
Ms. Fernando da Silva Machado [FAFIL-UFG]

do [objetivo], que tem a seu favor a prudência científica, pareceu-nos insuficiente para fundar uma metafísica da imaginação [...] Pareceu-nos então que essa transubjetividade da imagem não podia ser compreendida em sua essência só pelos hábitos das referências objetivas. Só a fenomenologia - isto é, o levar em conta a partida da imagem numa consciência individual — pode ajudar-nos a restituir a subjetividade das imagens e a medir a amplitude, a força, o sentido da transubjetividade da imagem (BACHELARD, 1978, p.184-185).

Entendemos que o único caminho a ser percorrido na tentativa de restituir e capturar a essência da imaginação e das imagens seria por meio de um método fenomenológico, que em si não se assemelha absolutamente em nada com o método psicanalítico usado anteriormente. O mérito de uma fenomenologia da imaginação consiste na exclusão das considerações causais da interpretação psicanalítica da matéria, assim como, da revisão das noções de arquétipo e do rastreamento da imagem-objeto em seu ponto de partida, em seu estado genuíno. Segundo Bachelard, o método fenomenológico é o único "capaz de captar a imagem enquanto atualidade" (BARBOSA; BULCÃO, p. 48). Portanto, todos estes fatores não fazem nada mais que fundar uma metafísica da imaginação através do colhimento direta e imediato das imagens (QUILLET, p.100-101). Embora opostas, imagem e conceito, em todo seu dinamismo, tornam-se criadoras de mundos e de realidades. Como disse Lecourt (1978, p.40), a teoria poética, de certa maneira, se projeta como uma realidade que preenche certas ausências e carências dos conceitos epistemológicos. Diríamos que o mesmo fluxo acontece entre epistemologia em direção à poética, preenchendo o buraco deixado pelas teorias estéticas e análises literárias que primam pelo excesso de abstração, daí a validade das obras sobre a imaginação material do autor. Todavia, não aprofundaremos no campo fenomenológico do pensamento bachelardiano porque não queremos nos desviar demais de nossas preocupações centrais sobre a noção de tempo poético em sua fase noturna.

\section{O que é isso meditar ?}

Em sua filosofia metafísica ou poética, para além de sua reflexão epistemológica, Bachelard ambicionou desde sempre definir o que é o ato de filosofar. Segundo o pensador, em uma de suas caracterizações prévias, longe de ser tomado como categórica, pensar consiste em aderir a uma "hesitação contínua, 
Poesia, instante vertical e solidão na fenomenologia poética de Gaston Bachelard
Ms. Fernando da Silva Machado [FAFIL-UFG]

muito surda, mesmo quando tem as pomposas garantias dogmáticas, mesmo quando avança recua em si mesmo" (BACHELARD, 1986, p.191). Pode parecer banal recapitular a definição dada pelos manuais de filosofia para o que consiste ser pensar, todavia, repitamo-la: pensar é assumir uma meditação filosófica, fazendo com que esse ato de pensamento se torne a lida do sujeito filosofante. Partindo desta definição, estamos inclinados a sustentar que a explicação bachelardiana de filosofia não passa muito distante da nossa:

Viver as abstrações [...] Todos os pensamentos, os graves e os sutis, os apaixonados e os frios, os racionais e os imaginários fariam parte dessa meditação. Duvidar-se-ia com o espírito ou com o coração, sábia ou ingenuamente, metódica ou hiperbolicamente, sincera ou fingidamente (BACHELARD, 1986, p.191).

O que notamos na citação acima do autor é que para se estabelecer um princípio meditativo, faz-se necessário conciliar dialeticamente os sentimentos e pensamentos que acontecem em polos ambivalentes de nosso espírito. Tal conduta dialética, de modo algum é gratuita em Bachelard, pois o método filosófico bachelardiano que ampara as investigações desenvolvidas em ambas as vertentes de seu pensamento é estritamente dialético e denota muito mais o sentido de complementaridade do que de oposição, onde o conhecimento subjetivo e conhecimento objetivo trocam valores ad infinitum. Pois bem, a noção de "dialética" presente na reflexão bachelardiana adquiriu uma acepção muito específica, parece-nos, que é uma categoria que se transforma quase que por obrigação em um estilo de pensamento muito peculiar. Vadée, comentador da obra bachelardiana, ressalta pelo menos seis definições para o termo "dialética" que ocorrem na filosofia do pensador. A maioria dessas acepções que definem o termo "dialética" são aplicadas ao contexto epistemológico de sua obra, porém, a última definição deste conceito expõe a caracterização das dialéticas ditas puramente subjetivas ou psicológicas, por exemplo: razão e imaginação, obstáculos que se dão em pares, dialética do dia e da noite, dos conceitos e imagens, do real e irreal (VADÉE, 1975, p.167-168).

Para se atingir o estatuto mesmo do ato primeiro do filosofar devemos ter o direito de meditar, segundo Bachelard. Nessa conjectura, entra em voga na filosofia bachelardiana a adoção do que ele denomina ser o mais solitário pensamento do pensador que vive e pensa solitariamente e usufrui deste estado de solidão para meditar. "O melhor objeto é para o filósofo que sonha, uma perspec- 
Poesia, instante vertical e solidão na fenomenologia poética de Gaston Bachelard
Ms. Fernando da Silva Machado [FAFIL-UFG]

tiva onde se ordena toda sua personalidade, seus mais secretos e mais solitários pensamentos" (BACHELARD, 1986, p.193). Portanto, definiríamos o ato de filosofar como a permanência em um estado de meditação constante, de meditação primeira, e somente através da solidão o filósofo pode exercê-la. Todavia, uma pergunta crucial parece surgir: será que no contexto do pensamento bachelardiano, tendo em conta sua definição do que é meditar, seríamos nós, levados a interpretar que o filósofo se aproximaria do significado oriental budista do mesmo termo? Para responder sinteticamente essa pergunta diríamos: a definição de meditação em Bachelard não divide semelhanças com a definição oriental do termo, antes, o estado de meditação constante é fruto da solidão que induz a abertura de mundos através da poesia. "Pela solidão, a meditação tem toda sua eficácia do espanto" (BACHELARD, 1986, p.193). É importante ressaltarmos o termo espanto nesta citação. Se perguntarmos pelo impulso originário da filosofia, poderíamos dizer que ele inicia-se com o ato de espantar-se; e como não dizermos que o ato de meditar nada mais é do que uma maneira prudente de lidar com o espanto que atordoa e angustia o homem? Este "espanto" permite nosso "despertar" para a possibilidade de conhecermos a realidade mesma do mundo, constituindo assim, o papel crucial da filosofia enquanto filosofar.

Em seu livro O Direito de Sonhar, Bachelard comenta a respeito de uma anedota que o escritor Oscar Wilde gostava de narrar. Essa historieta nos revela precisamente a imagem do "espanto" que o filósofo buscava definir:

Por exemplo, uma meditação matinal é imediatamente um mundo a ser despertado. Para ilustrar o ingênuo dinamismo do devaneio da manhã, relemos esta história que Oscar Wilde gostava de contar: um santo que se levantava todos os dias muito antes do alvorecer orava a Deus para que Deus fizesse, também hoje, nascer o sol. Depois que alvorecia, orava a Deus para lhe agradecer por ter atendido sua prece. Uma noite, tomado por um pesado sono, o santo esqueceu sua prece noturna. Ao despertar, o sol estava muito alto, acima do horizonte. Então, após um instante de confusão, o santo pôs-se a orar para agradecer a Deus que, apesar da culpada negligência de seu servo, havia mesmo assim feito o sol nascer (BACHELARD, 1986, p.194). 
Poesia, instante vertical e solidão na fenomenologia poética de Gaston Bachelard
Ms. Fernando da Silva Machado [FAFIL-UFG]

O que nos chama a atenção nessa narrativa é o momento em que o personagem experimenta o que o escritor denominou como sendo um "instante de confusão". Apesar de toda sua displicência, por ter sido tomado por um sono profundo que o fez acordar depois que o sol havia nascido, o santo se "espanta" porque muito tempo havia passado desde o alvorecer e porque ele pôde viver através de sua solidão o instante que pesa a culpa em sua consciência por ter sido negligente. Neste instante revelador da realidade que o cerca, o santo experimenta o estado de primeira meditação ao "reintroduzir a solidão inicial" (BACHELARD, 1986, p.198). Sendo assim, a ideia de tempo é fundamental para a constituição da obra literária que faz com que o homem medite e se espante, de maneira análoga como se espantou o santo de Wilde. Bachelard diz: tempo é hesitação, “juventude e morte, fermata. Ele poderia se suspender" (BACHELARD, 1986, p.191). O tempo hesita porque retorna, suspende e morre (ideia que facilmente acusaria as leituras nietzschianas por parte de Bachelard). Pensar em um tempo que hesita é se desvincular dos ritmos ocasionais, é recolocar a vida, por intermédio de uma suspensão temporal (fermata), em plena expectativa de criação de um novo pensamento que um dia hesitará, mas que não mais pode recuar diante do tempo, a não ser que um novo instante o "ensurdeça", reinserindo em seu lugar outra vox principalis, ou será um outro cantus firmus? Destarte, meditar é insurgir em um tempo de partida e de hesitação que nos permite a heresia racionalista de "não mais pensar, diante de um mundo que não pensa" (BACHELARD, 1986, p.193). Reintroduzindo a solidão nas imagens poéticas da noite em seu artigo Fragmento do diário do homem (publicado na coletânea $O$ direito de Sonhar supracitada), Bachelard chega a afirmar que: "A solidão é tua duração. Tua solidão é tua própria morte que dura em tua vida, sob tua vida" (BACHELARD, 1986, p.196). Este estado de solipsismo cálido desperto na poética bachelardiana (circunscrito pelas imagens que brotam do canto de um quarto qualquer, evocadas por um leitor qualquer, que pelas folhas de um livro se instrui) é definitivamente contrário ao estado de espírito dos homens da ciência que se instruem pelo pensamento racional-intelectualista, mas que, no entanto, raramente meditam (vejam que ao falarmos de meditação não nos referimos ao pensamento do homo mathematicus, antes, falamos do pensamento que hesita e ressurge assim como o tempo que nasce e que morre, portanto, meditar e racionalizar são acepções contrárias em certa medida para Bachelard). Tal estado, que nos entrega à solidão pela e na poesia, poderia facilmente ser definido como avesso àquela máxima de "socialização" dos membros da cidade científica proferida por Bachelard em seus 
Poesia, instante vertical e solidão na fenomenologia poética de Gaston Bachelard
Ms. Fernando da Silva Machado [FAFIL-UFG]

estudos epistemológicos. Lá, a comunhão entre os homens instruídos requer a socialização de sua prática, sem ela não haveria ciência alguma. $\mathrm{O}$ aspecto de distanciamento do mundo, "da defesa da vida retirada e fortalecimento da vida moral" pertence tão somente ao campo da literatura e da filosofia:

[...] a dimensão solitária, de isolamento e de esquecimento conota essa ligação que se revela uma condição existencial, bem reconhecida na figura do pensador solitário de Bar-sur-Aube, um emblema de sua personalidade intelectual, que se opõe a experiência socializada do fluxo da duração na relação do sujeito com o mundo (POLLIZI, 2006, p.60).

\section{Solidão}

De certa maneira abordar o tema da solidão no pensamento bachelardiano já é evocar a reflexão daquele que é e se encontra só. O leitor frente às páginas de um livro, embaixo da luz de uma vela, sob essa "dupla ilha de luz", se responsabiliza pelas fantasias e devaneios oferecidos pelos poetas: "faço-me só, profundamente só, com a solidão de um outro" (BACHELARD, 1989, p.57). A função da poesia não é nos transformar (a transformação está reservada a apenas alguns poetas solitários que estão permanentemente mudando), antes, a beleza não pode reproduzir-se, precisa ser produzida, comentava Lescure (2015, p.153), ao relembrar alguns trechos das obras de Bachelard. Para nós, a solidão é o estado de espírito que percorre toda a filosofia bachelardiana desde suas obras epistemológicas (mesmo que a constituição de uma cidade científica seja necessária é o estado de solidão que participa do primeiro instante de criação teórica do cientista), passando pelas obras de imaginação material até suas obras fenomenológicas. A solidão é um estado que solicita o valor e a ascese do trabalho e "nos devolve à primitividade do mundo" (BACHELARD, 1986, p.193).

O ser sonhado concentra-se aí para o ser que trabalha. Que reconforto, que nostalgia lembrar-se dos quartos pequenos onde se trabalhava, onde se tinha energia para trabalhar bem. O verdadeiro espaço do trabalho solitário é dentro de um quarto pequeno, no círculo iluminado pela lâmpada (BACHELARD, 1989, p.108). 
Poesia, instante vertical e solidão na fenomenologia poética de Gaston Bachelard
Ms. Fernando da Silva Machado [FAFIL-UFG]

O trabalho, o estudo, a solidão, projetam a imagem poética que se faz escrita e que ultrapassa o pensamento puro. Pela solidão da leitura Bachelard confere toda a positividade de um universo já existente, mas que para nós parece muito pouco consciente, apesar de importante; ele é o universo "bibliomenal", se nos é permito adotar o termo cunhado por Quillet, comentador da obra bachelardiana. "O mundo está intencionalmente circunscrito a uma mesa e a seus arredores: minha lâmpada e meu papel branco" (QUILLET, 1977, p.122). Só pelo estudo eliminamos as duplas trevas do espírito e da noite: "antes de pensar é preciso estudar. Só os filósofos pensam antes de estudar” (BACHELARD, 1989, p.58). Pela solidão, em um registro de pensamento para além de seu alcance poético, o ato de filosofar deixa de ser a atividade dos "filósofos de escolas".

Em a Intuição do Instante Bachelard define no último capítulo que a arte, assim como a razão, já é lugar de solidão. Uma solidão que rompe com suas amarras e que retorna mais uma vez ao seu lugar de origem: à vida e ao pensamento. Portanto, a arte em sua forma poética evoca uma solitária voz que brota do fundo de nossos corações, cantando perpetuamente seus dramas e alegrias. Citando Roupnel', Bachelard pronuncia: pela arte "o senso de harmonia que nos restitui ao ritmo do mundo e nos devolve ao infinito que nos chama" (BACHELARD, 2010, p.91) acaba por nos tornar mais uma vez "partícipes do ritmo absoluto em que se desenvolve o fenômeno completo do mundo" (BACHELARD, 2010, p.91). Segundo Bachelard, a poesia cultiva aquilo que no pensamento de Roupnel é chamado de melancolia profunda. A melancolia é uma necessidade metafísica. Tão-somente pelo caráter dramático desse sentimento vivenciamos em um mesmo pensamento a dialética do pesar e a esperança. Em um instante poético, tomado pelo nada absoluto que há entre as duas pontas de uma mesma fagulha temporal, a vida do ser do homem é revelada em todas as suas "contradições íntimas". A vida, somente quando aceita em suas ambivalências sentimentais, é acolhida por seus "instantes vividos" (BACHELARD, 2010, p.91). Em Siloë, só o amor faz com que a duração progrida à medida que nos direcionamos à fonte única $\mathrm{e}$ misteriosa de seu leito. $\mathrm{O}$ amor dos romancistas é demasiado fácil e ingênuo: são amores rápidos e eternos, amor de "amadores". Todavia, segundo Bachelard, só quem sofre a melancolia do instante de saudade e sofrimento de um amor perdido pode dizer que conheceu a "felicidade pura": "é porque se ama e se sofre que o tempo prolonga em nós o eu que dura. [...] Pelo próprio fato de amarmos e de sofremos, estamos inscritos no caminho do universal e do firmamento" (BACHELARD, 2010, p.86-87). E quem melhor se instala na ambivalência da ausência

1 ROUPNEL, G. Siloë. p.198. 
Poesia, instante vertical e solidão na fenomenologia poética de Gaston Bachelard
Ms. Fernando da Silva Machado [FAFIL-UFG]

e da felicidade senão aquele que vive no instante congênito da criação poética? Quão pouco profundo e dramático seria se Wagner tivesse criado uma Isolda apaixonada por um Tristão vivo - sobrevivente em Júbilo! "Morrer por amor, no amor, como a borboleta na chama, não é realizar a síntese de Eros e Tânatos?" (BACHELARD, 1989, p.55). E aqui, mais uma vez, neste ponto preciso, ecoam os ensinamentos nietzschianos sobre a tragédia e o caráter dramático da arte e da vida captado em substância por Bachelard. Sobre a lei fundamental da tragédia, que nós homens devemos tê-la como tarefa a cumprir em vista da superação de nós mesmos, Nietzsche pronuncia: “devemos desaprender a terrível angústia que nos causam a morte e o tempo, pois, no mais breve instante, na parcela mais íntima de sua vida pode sobrevir um acontecimento sagrado que compense e, bem além disso, todas as lutas e todas as misérias - esse é o estado de alma trágico" (NIETZSCHE, 2009, p.50). Por conseguinte, a poesia faz-nos fugir de um mundo onde a vida é fácil e romanesca, de uma vida onde se procura o sentido dela própria nos intermináveis preâmbulos dos livros metafísicos dos filósofos. Antes mesmo dos métodos e leis universais a priori, a poesia "tem necessidade de um prelúdio de silêncio" (BACHELARD, 2010, p.94). É por outro domínio metafísico que não aquele puramente filosófico que a poesia insinua-se como o "lugar de nossa vida dialética" (BACHELARD, 2010, p.94). "É para construir um instante complexo, para atar, nesse átimo, simultaneidades numerosas, que o poeta destrói a continuidade simples do tempo encadeado" (BACHELARD, 2010, p.94).

\section{Instante poético}

Em seu belo artigo Instante poético e instante metafísico Bachelard diferenciou o tempo poético denominado de vertical de um tempo poético tido como horizontal. A poesia prosódica privilegia a sucessão e a regularidade, suas imagens constituem uma vida social descritiva, "escorregadia" e "linear", fruto de um pensamento enunciativo e contínuo. Já a poesia vertical, adjudicada por um instante profundo, encontra sua dramaticidade metafísica essencial em um tempo rompante interrompido pelas imagens fragmentadas dos poetas. A dialética dos sentimentos incide sobre o instante poético por meio de uma "relação harmônica dos dois contrários": razão e paixão de um solitário. Como disse Bachelard: "o instante poético é a consciência de uma ambivalência” (BACHELARD, 2010, p.99). Se pelo instante poético somos entregues ao fluxo ascendente e descendente da sensação mais íntima de nosso ser, jamais podemos concordar com as doxografias ligeiras produzidas pelo senso comum 
Poesia, instante vertical e solidão na fenomenologia poética de Gaston Bachelard
Ms. Fernando da Silva Machado [FAFIL-UFG]

que entendem ambivalência como antítese, pois o tempo vertical é ambivalente na medida em que se torna simultaneidade dialética. Já o tempo horizontal não cessa de tornar-se insignificante, antitético e corriqueiro. É preciso, portanto, reconhecer o encanto do tempo vertical, como Tales (em Teeteto de Platão) o fez ao contemplar o infinito e o firmamento, se distanciando do tempo das coisas simples e das preocupações utilitaristas da rapariga Trácia; ou ele olha para o alto contemplando as estrelas ou cai dentro do buraco, ou ele é tomado por forças ascendentes ou descendentes, impossível mesmo seria ele olhar para o horizonte. Pensar o tempo e a vida nunca foi uma tarefa fácil como defendera vorazmente Bergson em seu ensaio Introdução à filosofia, pensar e viver não são atos simples, pois fazem parte de um desmesurado exercício cosmológico, onde humanos empenhados em sua tarefa racionalizante e poetizante entram em constante sintonia com um tempo vertical dramático e de decisão. Nesse ponto, entendemos o quanto a vida é dramática para Bachelard, tragédia no tempo, pois ela não pode escapar à força temporal e na maioria das vezes não consegue penetrá-lo ou arrombá-lo. Somente o poeta pode recusar o tempo horizontal esteticamente e inserir a vida no que o tempo vertical tem de mais orgânico e ameaçador. Bachelard definiu o modo como podemos nos desacorrentar das experiências de um tempo encadeado:

1) habituar-se a não referir o tempo próprio ao tempo dos outros - romper com os contextos sociais da duração; 2) habituar-se a não referir o tempo próprio ao tempo das coisas - romper com os contextos fenomênicos da duração; 3) habituar-se - duro exercício - a não referir o tempo próprio ao tempo da vida; não mais saber se o coração bate, se a alegria avança - romper os contextos vitais da duração (BACHELARD, 2010, p.96).

\section{A Poesia e seus leitores}

Se pudéssemos definir mais objetivamente o sentido latente da expressão tempo vertical poético em Bachelard, diríamos que é por ele, em vias de realização artística antecipadora, que o leitor se apodera dos poemas-imagens para não mais permanecer só. Sua solidão é a solidão da leitura, é o distanciamento dos ruídos ensurdecedores da cidade social. Em um tempo vertical, suspenso, silencioso, o homem assume-se enquanto projeto ontológico incompleto, entre- 
Poesia, instante vertical e solidão na fenomenologia poética de Gaston Bachelard
Ms. Fernando da Silva Machado [FAFIL-UFG]

gue ao devir, por realizar-se. A poesia faz com que o homem desça ao fundo de sua alma, tanto quanto, com que suba ao infinito talesiano, se nos é permitido novamente fazer referência ao interlocutor platônico. "A linguagem é um modo de existência. É por que se exercita a descoberta. Ela não reproduz o mundo, ela o produz" (LESCURE, 2015, p.143). Portanto, no fluxo descensional e ascensional do tempo poético-vertical o homem retoma o que já se sabe: assim como o poema, ele constitui-se enquanto obra aberta (opus metaphysicum), não fixada; ele próprio permanece em vias de se assumir como invenção de si: "Nós somos $\mathrm{o}$ animal que por si próprio se destina à sua descoberta. $\mathrm{Na}$ obra de Bachelard a novidade é um fator de realidade. Para ele a poesia se designa como uma das formas de audácia humana" (LESCURE, 2015, p.147). Contudo, perguntaríamos: como pode uma ontologia poética do homem, se não se impõe primeiramente a pergunta filosófica o que é o ser? Ela se coloca sim, porém, secretamente. Antes, essa pergunta precisa ser evocada e refletida, pois a tríade: o poeta, o leitor e a imagem mediada, constituem as várias temporalidades entreabertas que circundam e retornam aos espaços do mundo, cada qual participando dos instantes temporais que lhe são próprios e alternados. $\mathrm{O}$ leitor não responde à pergunta essencial da filosofia (o que é o ser?) filosoficamente, essa pergunta é estritamente filosófica, não lhe cabe respondê-la. Estar no mundo, já é desocultar o ser poeticamente (na acepção já conferida por Heidegger): hic e nunc, através do acontecimento instantâneo em um tempo vertical, por meio da linguagem-ação de que fala Bachelard em sua análise sobre a poesia de Lautréamont, poesia do músculo, do grito e dos nervos. Para completar: "o destino poético do homem é ser espelho da imensidão ou, de maneira mais precisa, a imensidão vem tomar consciência de si no homem" (BACHELARD, 1978, p.324).

\section{Conclusão}

Por fim, se nos é permitido refletir rapidamente sobre a unidade entre a vertente epistemológica e a vertente poética do pensamento bachelardiano, remataríamos que é pelo poder catártico da linguagem, tanto na ciência quanto na poesia, que estamos inclinamos a acreditar que o caráter de completude de sua obra foi conquistado pelo distanciamento dinâmico e intensivo entre os polos ambivalentes de sua filosofia. Pelo conflito e pela força, diurno e noturno se atraem e se repelem ad absolutum. É pela crença na força da linguagem da ciência enquanto história de sua discursividade entreposta pelos diversos mo- 
Poesia, instante vertical e solidão na fenomenologia poética de Gaston Bachelard
Ms. Fernando da Silva Machado [FAFIL-UFG]

mentos descontínuos de suas pesquisas, tanto quanto, pela poesia que lança o leitor em um tempo vertical, que Bachelard demonstra que a ambivalência de sua perspectiva filosófica não passa de um sintoma plástico e colateral das metamorfoses de sua alma; metamorfose necessária ao humano, à constituição do homem das 24 horas, pois só há progresso com transformação, se nos é permitido tomar de empréstimo uma máxima da ciência. Portanto, “o ser não é aquilo que se repete semelhante a si mesmo. Ele é aquilo que surge, aquilo que jorra, aquilo que emerge de sua própria ausência” (POULET, 1965, p.22). E onde mais surgiriam os traços íntimos do ser do homem senão a partir das imagens nascentes dos poetas, oferecidas instantaneamente, e contempladas, por sua vez, "por nós", leitores? "Por nós", entendemos, o eu solitário, que fique claro. Enquanto leitor, eu enfrento minha singularidade, me distancio da indústria cultural massificadora, sou coroado com o bom ostracismo pelos e dos célebres filósofos. E não é o texto em si e nem muito menos o poeta que desperta em nós a velha resposta ontológica procurada (como se pudesse!). É a quintessência recíproca entre a imagem evocada por "nos", leitores, em seus devaneios literários mais profundos que respondem quem somos agora neste instante vertical que já passou e se encerrou, contudo, uma resposta alcançada e idealizada por nós mesmos, pois segundo Lescure (2015, p.148), Bachelard "remarcou que, cientista ou poeta, o homem não está dado. Ele se faz".

Recebido em: 12.05.2016 Aprovado em: 30.07.2016

BACHELARD, G. A chama de uma vela. Tradução Glória C. Lins. Rio de Janeiro: Bertrand Brasil, 1989. A dialética da duração. Tradução Marcelo

Coelho. 2.ed. São Paulo: Ática, 1994. . A intuição do instante. Tradução Antonio de

P. Danesi. 2.ed. Campinas: Verus, 2010. A poética do espaço - col. Os Pensadores. Tradução Joaquim José Moura Ramos. 1.ed. São Paulo: Abril Cultural, 1978, p.181-354. Lautréamont. Tradução Fábio Ferreira de Almeida. Goiânia: Ricochete, 2013.
O direito de sonhar. Tradução J. A. M. Pessanha, J. Raas, M. I. Raposo, M. L. C. Monteiro. 2.ed. São Paulo: Difel, 1986.

BARBOSA, E; BULCÃO, M. Bachelard: pedagogia da razão, pedagogia da imaginação. 2.ed. Petrópolis: Vozes, 2004.

LECOURT, D. Bachelard ou le jour et la nuit. Paris: Grasset, 1974.

L'épistémologie historique de Gaston Bachelard. Paris: Vrin, 1978.

LESCURE, J. Introduction à la poétique de Bachelard. Paris: Stock, 2015. 
NIETZSCHE, F. Wagner em Beyreuth. Rio de Janeiro: Jorge Zahar, 2009.

POULET, G. Bachelard et la conscience de soi. Revue de métaphysique et de morale, n.1, janvier./mars. 1965.

QUILET, P. Introdução ao pensamento de Bachelard. Tradução César A. Fernandes. Rio de Janeiro: Jorge Zahar, 1977.

VADÉE, M. Bachelard ou le nouvel idéalisme épistémogique. Paris: Sociales, 1975.

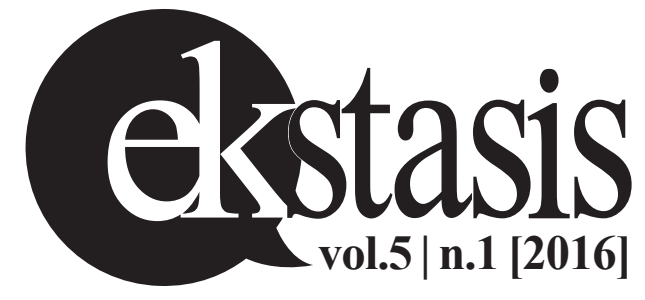

